\title{
O DIREITO COMO INTEGRIDADE E O ROMANCE EM CADEIA DE DWORKIN: DIÁLOGO COM A RESPOSTA ADEQUADA DE LENIO STRECK E COM A NOÇÃO DE ESPAÇO PÚBLICO DE HANNAH ARENDT
}

LAW AS INTEGRITY AND DWORKIN'S CHAIN ROMANCE: DIALOGUE WITH THE APPROPRIATE RESPONSE OF LENIO STRECK AND WITH THE NOTION OF PUBLIC SPACE BY HANNAH ARENDT

\author{
Gabrielle Valeri Soares ${ }^{1}$ \\ Jaqueline Valeri Soares ${ }^{2}$
}

\section{RESUMO}

Este estudo tem como finalidade analisar as conexões entre o modelo de tomada de decisão judicial de Ronald Dworkin, a resposta adequada de Lenio Streck e a noção de direitos humanos encampada por Hannah Arendt. Pretende-se demonstrar como o magistrado deve decidir à luz da figura do juiz Hércules e do exercício do romance em cadeia tecido por Dworkin. Busca-se explicitar o conteúdo do princípio legislativo de integridade - e seu necessário diálogo com a obra intitulada Origens do totalitarismo, de Hannah Arendt - bem como explanar acerca do princípio jurisdicional da integridade, sem deixar de abarcar as críticas tecidas ao juiz Hércules e a contribuição de Lenio Streck para a adequação do modelo de decisão judicial de Dworkin no sistema romanogermânico. A metodologia utilizada no presente artigo é dedutiva; quanto ao

\footnotetext{
1 Mestranda em Filosofia do Direito na Pontifícia Universidade Católica de São Paulo (PUCSP). Especialista em Direito Civil e Empresarial e em Direito e Processo do Trabalho pela Faculdade de Direito Professor Damásio de Jesus. Graduada em Direito pela Fundação Armando Álvares Penteado Advogada. E-mail: gabriellevaleriadv@gmail.com. ORCID: https://orcid.org/0000-0003-4956-1805. Endereço: Alameda Terracota, n. 215, Cj 518 e 519, sala 139, CEP: 09531-190, Bairro Cerâmica, São Caetano do Sul - SP.

${ }^{2}$ Graduanda em Direito pela Universidade Municipal de São Caetano do Sul (USCS). É estagiária do escritório Gabrielle Valeri Advocacia. Participou do Núcleo de Jurisprudência da Corte Interamericana de Direitos Humanos do Observatório de Violação de Direitos Humanos da USCS e, atualmente, desenvolve uma Iniciação Científica com enfoque em Saúde Pública. E-mail: jaquelinevaleri70@gmail.com. ORCID: https://orcid.org/0000-0002-8206-8070. Endereço: Alameda Terracota, n. 215, Cj 518 e 519, sala 139, CEP: 09531-190, Bairro Cerâmica, São Caetano do Sul - SP.
} 
procedimento, é uma pesquisa bibliográfica, mediante revisão de livros e artigos científicos. Os resultados da pesquisa realizada revelam que a comunidade de princípios referida por Ronald Dworkin tem amparo nas ideias de Hannah Arendt a respeito de espaço público, poder, direitos humanos e política. Conclui-se que a questão da ideia de resposta correta, empreendida por Dworkin e Streck, implicam em um reforço da comunidade de princípios e da efetivação de direitos fundamentais.

PALAVRAS-CHAVE: Decisão judicial; Dworkin; Comunidade de princípios; Resposta adequada; Lenio Streck.

\section{ABSTRACT}

This study aims to analyze the connections between Ronald Dworkin's model of judicial decision-making, Lenio Streck's adequate response and the notion of human rights assumed by Hannah Arendt. It is the intention to demonstrate how the magistrate should decide in light of the figure of judge Hercules and the exercise of the romance chain developed by Dworkin. The target is to explain the content of the legislative principle of integrity - and its necessary dialogue with the work Origins of totalitarism by Hannah Arendt - as well as explain about the jurisdictional principle of integrity, while including the criticisms made to judge Hercules and Lenio Streck's contribution to the adequacy of Dworkin's judicial decision model in the Roman-Germanic system. The methodology used in this article is deductive; as to proceedings, it is bibliographic by way of review of books and periodicals. The results of the research show that the community of principles mentioned by Ronald Dworkin has support in Hannah Arendt's ideas about public space, power, human rights and politics. It is concluded that the concern with the idea of a correct answer, undertaken by Dworkin and Streck implies a reinforcement of the community of principles and of the realization of fundamental rights.

KEYWORDS: Judicial decision; Dworkin; Community of principles; Adequate answer; Lenio Streck.

\section{INTRODUÇÃO}

A questão da tomada da decisão judicial é tema de grande relevância prática e teórica, na medida em que constitui ponto de encontro ao pretender-se explanar questões conexas ao Poder Judiciário, como é o caso da Teoria da Tripartição dos Poderes de Montesquieu ou, ainda, de inferências concernentes ao ativismo judicial. 
O presente artigo pretende analisar a teoria da tomada da decisão judicial de Ronald Dworkin a partir do desenvolvimento do princípio da integridade política e de princípio da integridade jurisdicional.

$\mathrm{Na}$ segunda seção abordar-se-á o princípio legislativo da integridade e a sua necessária conexão com a obra intitulada Origens do totalitarismo, de Hannah Arendt.

$\mathrm{Na}$ terceira seção, pretende-se desenvolver a noção de princípio jurisdicional da integridade e da ideia de romance em cadeia como modelo da decisão judicial, mediante a análise das dimensões da adequação e do valor. Adicionalmente, buscarse-á explicitar as diferenças entre o Direito visto como integridade e as visões construídas pelo pragmatismo e pelo convencionalismo.

Em seguida, na quarta seção, tenciona-se demonstrar como a figura do juiz Hércules, construída por Dworkin, decide em face de um caso difícil, sem deixar de fazer as competentes referências às críticas tecidas ao juiz Hércules e sua refutação. $A$ partir desta tônica, introduzir-se-á a contribuição de Lenio Streck, por ser uma adequação da teoria da tomada de decisão judicial construída por Dworkin com o sistema romano-germânico.

A metodologia utilizada no presente artigo é dedutiva; quanto ao procedimento é uma pesquisa bibliográfica, mediante a revisão de livros e artigos científicos. Com efeito, cogita-se produzir conhecimento útil na área jurídica, mediante contribuições advindas da Filosofia, da Teoria Geral do Direito e da Hermenêutica, bem como sugerir caminhos para futuras pesquisas que pretendam tratar do tema sub examine.

\section{PRINCÍPIO LEGISLATIVO DA INTEGRIDADE}

Na obra intitulada Império do Direito, de Ronald Dworkin, o Autor explica que há dois princípios de integridade política, quais sejam: (i) o princípio legislativo (exige que os legisladores tentem tornar o conjunto de leis moralmente coerente); e (ii) o princípio jurisdicional (demanda que a lei seja vista como coerente). As primeiras perguntas 
formuladas pelo Autor são: "a integridade, enquanto ideal político distinto, adapta-se à política norte-americana? A integridade, enquanto ideal político distinto, honra a política norte-americana?" (1999, p. 213). Primeiramente, o Autor ressalta que em uma sociedade utópica (perfeitamente justa e imparcial), a integridade não seria necessária como virtude política distinta.

$\mathrm{Na}$ política comum, dado que a integridade é aceita como ideal político independente (ao lado de outros ideais, como justiça, equidade e o devido processo legal), e, ao considerar que, diversas vezes, esses ideais entram em conflito, seria possível pensar que "às vezes, a equidade ou a justiça devem ser sacrificadas à integridade." (DWORKIN, 1999, p. 215). Neste passo, o Autor busca demonstrar que as práticas políticas estadunidenses aceitam a integridade como ideal distinto e, primeiramente, descarta a solução conciliatória, pois causaria consternação um direito que "tratasse acidentes similares ou ocasiões de discriminação racial ou aborto diferentemente, em bases arbitrárias." 1999, p. 217). No mesmo sentido, o Autor assevera que:

Pareceria decorrer de nossas convicções sobre a equidade que a legislação sobre essas questões morais não deveria restringir-se à aplicação da vontade da maioria numérica, como se seus pontos de vista fossem unânimes, mas que deveria ser também uma questão de negociações e acordos que permitissem uma representação proporcional de cada conjunto de opiniões no resultado. (1999, p. 216).

Quando o que está em pauta são questões de princípios, no entendimento do Autor, é seguido um modelo diferente de deliberação, no qual cada ponto de vista deve ter voz, de sorte que a decisão coletiva deve ser capaz de fundamentar-se em um "princípio coerente cuja influência se estenda então aos limites naturais de sua autoridade." (1999, p. 217).

Por conseguinte, o Autor conclui que se é necessário atingir uma espécie de meio-termo (tendo em vista o fato de que as pessoas não concordam a respeito do que 
DOI 10.20873/uft.2359-0106.2021.v8n2.p202-220

seria justo), então "é preciso chegar a um acordo sobre o sistema de justiça a ser adotado, em vez de um sistema de justiça fundado em concessões." (1999, p. 218).

Nestes termos, a solução conciliatória não poderia ser aceita, eis que o Estado personificado não pode agir de forma incoerente em termos de princípios. Assim, "o que a integridade condena é a incoerência de princípio entre os atos do Estado personificado." (DWORKIN, 1999, p. 223).

No tema das leis conciliatórias, o Autor pondera que:

[...] são as mais clamorosas violações do ideal de integridade, e não são desconhecidas em nossa história política. Em sua origem, a Constituição dos Estados Unidos continha exemplos odiosos: o problema da escravidão era regido por um acordo conciliatório mediante o qual se contavam três quintos da população de escravos de um estado para determinar sua representação no Congresso e para proibir que este limitasse o poder original dos estados de importar escravos, mas somente antes de 1808. A integridade é escarnecida não apenas em concessões específicas desse tipo, mas sempre que uma comunidade estabelece e aplica direitos diferentes, cada um dos quais coerente em si mesmo, mas que não podem ser defendidos em conjunto como expressão de uma série coerente de diferentes princípios de justiça, equidade ou devido processo legal. (1999, p. 223/224).

Nos Estados Unidos da América, a integridade seria uma questão de Direito constitucional em razão da cláusula de igual proteção contida na Décima Quarta Emenda, a qual, no entendimento de Dworkin, vedaria "conciliações internas sobre questões de princípios importantes." Assim, a "Suprema Corte se fundamenta na linguagem da igual proteção para derrubar a legislação estadual que reconhece direitos fundamentais para alguns e não para outros." (1999, p. 224). Com efeito, pensa-se a integridade tanto em termos regionais (dos Estados-membros), quanto em termos federais. É o que se depreende do excerto em que são feitas inferências acerca das decisões de ordem constitucional: 
DOI 10.20873/uft.2359-0106.2021.v8n2.p202-220

A Constituição norte-americana provê um sistema federal: reconhece os estados como comunidades políticas distintas e atribui-lhes soberania sobre muitas questões de princípio. [...] Cada estado federado fala com uma só voz, ainda que esta não esteja em harmonia com a de outros. Em um sistema federal, porém, a integridade impõe exigências às decisões de ordem superior, tomadas em nível constitucional, sobre a divisão do poder entre o nível nacional e os níveis locais. (DWORKIN, 1999, p. 225/226).

Ao abordar a defesa do princípio legislativo da integridade, o Autor infere que "[...] devemos defender o estilo geral de argumentação que considera a própria comunidade como um agente moral." (1999, p. 227); o pragmatismo poderia implicar na presunção de que o Estado não poderia ser visto como uma entidade com princípios, mas certamente como um conjunto de pessoas, cada qual com os seus próprios princípios. Assevera Dworkin, que a defesa da integridade deve ser encontrada "nas imediações da fraternidade, ou, para se usar seu nome mais difundido, da comunidade." (1999, p. 228).

A integridade seria capaz de conferir autoridade moral à sociedade política como monopolizadora da força coercitiva, de forma que um "Estado que aceita a integridade como ideal político tem um argumento melhor em favor da legitimidade que um Estado que não a aceite." (1999, p. 232); nesta acepção, o Autor entende que a defesa da legitimidade é encontrada na fraternidade:

[...] a melhor defesa da legitimidade política - o direito de uma comunidade política de tratar seus membros como tendo obrigações em virtude de decisões coletivas da comunidade - vai ser encontrada não onde os filósofos esperaram encontrá-la - no árido terreno dos contratos, dos deveres de justiça ou das obrigações de jogo limpo, que poderiam ser válidos entre os estranhos -, mas no campo mais fértil da fraternidade, da comunidade e de suas obrigações concomitantes. (p. 249/250).

Portanto, o Autor volta a sua atenção ao seguinte questionamento: qual forma deve assumir essa comunidade política? Somente uma comunidade de princípios atende a quatro requisitos concomitantes, quais sejam: (i) as obrigações do grupo são 
DOI 10.20873/uft.2359-0106.2021.v8n2.p202-220

especiais; (ii) as responsabilidades são pessoais (de todos os membros); (iii) há uma responsabilidade geral (preocupação com o bem-estar de todo o grupo); e (iv) as práticas do grupo mostram igual interesse por todos os membros. O modelo da comunidade de princípios, na visão de Dworkin, é calcado na ideia de que os indivíduos apenas fazem parte de uma comunidade política genuína quando:

[...] aceitam que seus destinos estão fortemente ligados da seguinte maneira: aceitam que são governadas por princípios comuns, e não apenas por regras criadas por um acordo político. [...] Uma associação de princípios não é, automaticamente, uma comunidade justa; [...], Mas o modelo dos princípios satisfaz as condições da verdadeira comunidade melhor do que qualquer outro modelo de comunidade possível para pessoas que divergem sobre a justiça e equidade a serem adotadas. (1999, p. 254).

A comunidade de princípios, por ser o modelo capaz de proporcionar um terreno comum para as divergências, dialoga com a ideia de espaço público, de poder e liberdade de Hannah Arendt, que desvincula a ideia de poder da noção de violência, na medida em que infere ser o poder a faculdade de alcançar-se um acordo sobre a ação comum, que apenas efetiva-se por meio da convivência pacífica entre os homens; dessarte, a política e o poder estariam imbricados na manifestação do bem comum.

A liberdade, na concepção de Hannah Arendt, consubstancia-se no exercício da ação humana e na decisão em conjunto com os demais. Na obra intitulada Origens do totalitarismo, de sua autoria, demonstra-se que na Alemanha nazista houve uma campanha de desnacionalização do povo judeu. A partir deste contexto a Autora conclui que a cidadania é o "direito a ter direitos". Assim, desvela-se que o direito a ter direitos é o direito de pertencer a uma comunidade política e de, portanto, acessar esse espaço público, de forma a não restar solitário:

Enquanto o isolamento se refere apenas ao terreno político da vida, a solidão se refere à vida humana como um todo. O governo totalitário, como todas as tiranias, certamente não poderia existir sem destruir a esfera da vida pública, isto é, sem destruir, através do isolamento dos homens, as suas capacidades políticas. Mas o domínio totalitário como forma de governo é novo no sentido de que não se contenta com esse isolamento, e destrói também a vida privada. 
Baseia-se na solidão, na experiência de não se pertencer ao mundo, que é uma das mais radicais e desesperadas experiências que o homem pode ter. (1989, p. 527).

Hannah Arendt explica que a solidão é tão insuportável porque implica na "perda do próprio eu, que pode realizar-se quando está a sós, mas cuja identidade só é confirmada pela companhia confiante e fidedigna dos meus iguais" (1989, p. 529). Antes do surgimento do Direito Internacional de Direitos Humanos, a nacionalidade era uma condição prévia para exercício da cidadania. O surgimento dessa proteção internacional integrou os apátridas ao mundo jurídico, os quais passaram a poder exercer os seus direitos em igualdade de condições com os cidadãos de determinado Estado. Assim, a condição sine qua non para o reconhecimento de um ser humano como sujeito de direitos passou a ser somente a condição de humano, não mais exigindo-se vínculo jurídico com um determinado Estado.

O modelo da comunidade de princípios diverge de outros dois modelos de comunidade: o modelo de regras (membros da comunidade aceitam o compromisso geral de obedecer às regras estabelecidas, de um modo que é próprio dessa comunidade) e o modelo no qual os integrantes da comunidade tratam a sua associação apenas como um acidente de fato da história e da geografia. (DWORKIN, 1999, p. 252/253).

Conclui-se que a comunidade de princípios pode ser identificada como o oposto de uma sociedade utópica (justa e perfeitamente imparcial). Com efeito, os ideais de justiça e equidade - na política comum - entram em conflito e, portanto, a negociação entre os grupos da sociedade, em prol de uma legislação que não sirva somente à vontade de uma maioria numérica, torna-se imprescindível. A comunidade de princípios, por ser um terreno que aceita a divergência de ideias, pode ser relacionada com os pressupostos de Arendt, tendo em vista que a Autora desvincula a concepção do poder da noção de violência, na medida em que o real poder traduz-se na ação capaz de alcançar um acordo comum entre os indivíduos da sociedade. 
Analisa-se na próxima seção o princípio jurisdicional da integridade, que guarda intrínseca relação com a questão da tomada da decisão judicial pelo magistrado à luz do pensamento de Dworkin. Buscar-se-á responder à seguinte pergunta: no que consiste o princípio jurisdicional da integridade? E em qual medida este princípio difere do pragmatismo e do convencionalismo?

\section{O PRINCÍPIO JURISDICIONAL DA INTEGRIDADE E O ROMANCE EM CADEIA}

O princípio jurisdicional da integridade demanda que os juízes tratem o sistema de normas públicas vigentes, como se este de fato expressasse e respeitasse um conjunto coerente de princípios e, com este propósito, que interpretassem as normas de maneira a descobrir normas implícitas entre e sob as normas explícitas. (DWORKIN, 1999, p. 261). Na mesma linha de raciocínio, o Autor entende que o "juiz que aceitar a integridade pensará que o direito que este define estabelece os direitos genuínos que os litigantes têm a uma decisão dele."; adicionalmente, o direito como integridade "nega que as manifestações do direito sejam relatos factuais do convencionalismo, voltados para o passado, ou programas instrumentais do pragmatismo jurídico, voltados para o futuro." (1999, p. 263/271).

O princípio jurisdicional da integridade seria utilizado para auxiliar os juízes a reconhecer determinados deveres e direitos, partindo-se do pressuposto de que estes seriam produtos de uma comunidade personificada. Neste aspecto, o Direito como integridade mostra que as proposições jurídicas são verdadeiras quando advindas de determinados princípios (devido processo legal, equidade e justiça), os quais oferecem uma melhor interpretação da prática jurídica. A prática jurídica, nesta acepção, poderá ser vista de um melhor ângulo ao supor-se que a comunidade aceitou determinado princípio: 
Decidir se o direito vai assegurar à sra. McLoughlin uma indenização pelos prejuízos sofridos, por exemplo, equivale a decidir se vemos a prática jurídica sob sua melhor luz a partir do momento em que supomos que a comunidade aceitou o princípio de que as pessoas na situação dela têm o direito a ser indenizadas. (DWORKIN, 1999, p. 272).

Antes de discorrer acerca do Direito como integridade, o Autor debruça-se sobre as questões atinentes ao convencionalismo e ao pragmatismo. convencionalismo consiste no estudo de casos precedentes pelos magistrados, sem a necessidade de contínua reinterpretação do registro legislativo como um todo. De outro lado, o pragmatismo induz o magistrado a pensar além da matéria jurídica, com um olhar direcionado ao futuro e ao bem-estar comunitário. Desse modo, o Autor afirma que o Direito como integridade seria mais interpretativo, porquanto trilharia caminhos não percorridos pelas correntes convencionalista ou pragmática, na medida em que exige (do magistrado) uma abrangente interpretação da prática jurídica e de sua fonte. O juiz teria de continuar "interpretando o mesmo material que ele próprio afirma ter interpretado com sucesso" (1999, p. 273). Sublinha-se que o Direito como integridade guarda um relevante relacionamento com a história; inicia-se no presente e volta-se para o passado com a finalidade de organizar e justificar a prática jurídica atual, de modo que se garanta uma melhor regra para o futuro, o que possibilita concomitantemente a justificação do que se realizou no passado. No mesmo sentido, o Autor entende que:

O direito como integridade, portanto, começa no presente e só se volta para o passado na medida em que seu enfoque contemporâneo assim o determine. Não pretende recuperar, mesmo para o direito atual, os ideais ou objetivos práticos dos políticos que primeiro o criaram. Pretende, sim, justificar o que eles fizeram. (1999, p. 274).

Ao abordar-se a prática atual, afirma-se que esta "pode ser organizada e justificada por princípios suficientemente atraentes para oferecer um futuro honrado" 
(DWORKIN, 1999, p. 274), o que torna possível introduzir o modelo de decisão judicial elaborado pelo Autor. A tomada da decisão judicial passa a ser comparada ao denominado romance em cadeia, em que um grupo de romancistas tem a tarefa de escrever um "romance em série; cada romancista da cadeia interpreta os capítulos que recebeu para escrever um novo capítulo que é então acrescentado ao que recebe o romancista seguinte [...]" (1999, p. 276). A complexidade da tarefa do romance em cadeia - capaz de exigir do romancista seguinte que escreva o seu capítulo de forma a desenvolver o melhor romance possível - assemelha-se à tarefa de decidir um caso difícil de Direito como integridade. (1999, p. 276).

Os magistrados, ao exercerem uma função semelhante à atividade dos romancistas em cadeia, devem buscar escrever um romance unificado - a melhor obra possível - como se pertencesse a um único autor; observa-se que o juiz deve perguntar-se qual interpretação torna a obra de arte melhor como um todo:

[...] espera-se que os romancistas levem mais a sério suas responsabilidades de continuidade; devem criar em conjunto, até onde for possível, um só romance unificado que seja da melhor qualidade possível [...]. Deve tentar criar o melhor romance possível como se fosse obra de um único autor, e não, como na verdade é o caso, como produto de muitas mãos diferentes. (DWORKIN, 1999, p. 276).

Com base neste entendimento, a estrutura interpretativa a ser seguida pelo magistrado é dividida em duas dimensões: A primeira seria a dimensão da adequação, na qual a interpretação adotada deve ser imbuída de fluidez (em relação ao texto pretérito), com poder explicativo geral e de modo a manter a coerência formal com o que já foi escrito. Na mesma linha:

Ele não pode adotar nenhuma interpretação, por mais complexa que seja, se acredita que nenhum autor que se põe a escrever um romance com as deferentes leituras de personagem, trama, tema e objetivo que essa 
interpretação descreve, poderia ter escrito, de maneira substancial, o texto que Ihe foi entregue. (DWORKIN, p. 277).

A segunda dimensão, por sua vez, é a dimensão do valor, porquanto corresponderia ao julgamento, por parte do juiz, de quais leituras possíveis ajustam-se melhor à obra em desenvolvimento depois de considerados todos os aspectos da questão; ou seja, trata-se de responder à pergunta: qual das leituras torna o romance melhor? É o que se evidencia no seguinte excerto: "A segunda dimensão da interpretação vai exigir-lhe então que julgue qual dessas leituras possíveis se ajusta melhor à obra em desenvolvimento [...]" (DWORKIN, p. 278).

A partir da analogia do romance em cadeia, o Autor assinala que os juízes, mesmo em face dos chamados hard cases, não estão autorizados a simplesmente criar Direito novo, eis que, no entendimento de Bittar, "o juiz não está autorizado a criar uma estória desvinculada de sua escrita anterior", não podendo nem mesmo "se desvencilhar do dever de considerar a coerência narrativa da ordem com a qual processa a estória ou the põe um término." (2019, p. 552).

Advoga-se pela existência de uma resposta correta em casos difíceis; aceita-se o desafio imposto pelo ceticismo interior (conforme será abordado adiante) e rechaçase a ideia de discricionariedade positivista, porquanto se concebe o Direito como um fenômeno interpretativo.

Assim, nos casos difíceis, cabe ao magistrado construir as suas conviç̧ões jurídicas e chegar a uma conclusão acerca do que o Direito determina para o caso concreto a ele apresentado. A assimilação do magistrado à figura de um romancista em cadeia - que busca criar o melhor romance unificado - permite concluir que o juiz deve sempre reinterpretar os casos pretéritos, a fim de chegar à melhor decisão no presente, sem deixar de considerar as suas implicações futuras.

Ao demonstrar o exercício interpretativo próprio do princípio jurisdicional da integridade, Dworkin cria o denominado juiz Hércules, o qual, por sua vez, não está 
DOI 10.20873/uft.2359-0106.2021.v8n2.p202-220

isento de críticas. A próxima seção dedica-se ao estudo do exercício interpretativo do juiz Hércules, além de expor as críticas a ele tecidas e as respostas conferidas.

\section{A TOMADA DA DECISÃO JUDICIAL: O JUIZ HÉRCULES, AS CRÍTICAS E O DIÁLOGO COM A OBRA DE LÊNIO STRECK}

O juiz Hércules é uma figura "de capacidade e paciência sobre-humanas, que aceita o direito como integridade" e que foi utilizada por Dworkin para demonstrar como deve ser a estrutura da interpretação jurídica. (2002, p. 265).

Assevera Bittar que "Hércules é aquele herói que consagra toda a força da própria reflexão sobre a equidade levada adiante por Ronald Dworkin"; ao aplicar o Direito, age "como a lei ou o precedente exigem, embora tomando suas decisões com convicção pessoal, sem que estas tenham força independente dos argumentos racionais utilizados para justificar o raciocínio judicial utilizado..." (2019, p. 554).

Os casos difíceis (hard cases) surgem, na ótica de Dworkin, quando ocorre a análise preliminar feita pelo juiz à luz de um caso concreto, emergir duas ou mais interpretações de uma lei ou decisão, em cuja hipótese o juiz deverá operar uma escolha entre as interpretações aceitáveis, questionando-se, nesse processo, acerca de qual interpretação representa a estrutura das instituições e decisões da comunidade. Com o propósito de ilustrar essa temática, Dworkin propõe que o juiz Hércules decida o caso Mcloughin (Mcloughin v. O' Brian).

Em termos esquemáticos, Hércules começa o seu empreendimento mediante a seleção de hipóteses de interpretação dos casos precedentes. No caso Mcloughin, $\mathrm{O}$ juiz considera seis hipóteses preliminares. Nesta questão, Hércules deve proceder à verificação de cada hipótese soerguida e perguntar a cada uma delas: "uma pessoa poderia ter dado os vereditos dos casos precedentes se estivesse coerente e conscientemente, aplicando os princípios subjacentes a cada interpretação?" Ao responder a tal indagação, o juiz Hércules conclui que somente as hipóteses quatro, 
cinco e seis sobrevivem ao teste. A próxima pergunta a ser dirigida às hipóteses remanescentes é: "qual dessas hipóteses deve ser excluída por ser incompatível com a totalidade da prática jurídica?"

Nesta fase, somente as hipóteses cinco e seis são bem-sucedidas. A escolha final entre as hipóteses cinco e seis dependerá das convicções de Hércules a respeito das duas virtudes constitutivas da moral política, quais sejam, a justiça e a equidade. (DWORKIN, 1999, p. 290/298). O juiz Hércules, entretanto, não está livre de críticas, as quais Dworkin se propõe a responder.

As críticas (e seus respectivos contrapontos) ao juiz Hércules podem ser assim sintetizadas:

(i) a interpretação correta das decisões anteriores pode ser atingida por meios neutros, por tratar-se apenas de descobrir quais foram os princípios utilizados pelos juízes do passado. Hércules responde que esta crítica também tem as suas motivações políticas, porquanto implica que as interpretações devam corresponder às intenções dos juízes do passado;

(ii) as interpretações que satisfazem ao teste da adequação são igualmente válidas, não havendo uma interpretação melhor do que a outra, ao que Hércules replica os fundamentos do Direito como integridade encontram-se contidos na própria integridade, ou seja, na melhor interpretação construtiva das decisões do passado; (DWORKIN, 1999, p. 309/331);

(iii) não seria justo que a resposta de Hércules fosse tida como definitiva se aqueles que pensam de forma diferente não tiveram a chance de sustentar os seus argumentos. Mesmo que haja divergência, cada juiz ainda confirmaria e reforçaria a comunidade de princípios ao esforçar-se para construir a sua própria opinião;

(iv) o ceticismo interior implica na crítica de que a prática jurídica seria por demais contraditória e, portanto, incapaz de oferecer qualquer interpretação coerente; contudo, Hércules admite a possibilidade de entrever-se um conjunto de princípios plausíveis capaz de oferecer uma interpretação aceitável; e 
DOI 10.20873/uft.2359-0106.2021.v8n2.p202-220

(v) A última crítica ao juiz Hércules reside no que Dworkin denomina Estudos Jurídicos Críticos. Nesta linha, em seu viés filosófico, a crítica afirma que diferentes ideologias produziram partes diferentes do Direito, o que implicaria em contradições fundamentais de princípio, de forma que Hércules não poderia impor uma estrutura coerente ao Direito em sua totalidade. O Autor afirma que esta postura apenas prevalecerá se o crítico tentar buscar uma solução menos cética e, no seu caminho, afirmar que fracassou. (1999, p. 309/331).

A teoria da tomada da decisão judicial no sistema common law foi desenvolvida por Dworkin e constitui-se em uma importante crítica ao "modelo do positivismo jurídico e à analítica do discurso jurídico, de civil law (Hans Kelsen e Norberto Bobbio) ou de common law (John Austin e Herbert Hart)." (BITTAR, 2019, p. 545). Não se busca, no presente artigo, desenhar o debate travado entre Hart e Dworkin (notadamente nas obras intituladas Conceito de Direito, de Hart, e Levando os direitos a sério, de Dworkin), mas certamente demonstrar as compatibilizações feitas por Lenio Streck à teoria da tomada da decisão judicial de Dworkin no sistema romano-germânico. Lenio Streck infere que:

A discussão sobre a possibilidade e necessidade de respostas corretas no Direito deita raízes na história da filosofia e na própria discussão fundamental sobre a verdade. Não por acaso, o debate jurídico contemporâneo retoma a luta contra os diversos tipos de ceticismo, tentando não reincidir no seu oposto ingênuo que defenderia fundamentos últimos e absolutos para o conhecimento ("formalismos", "jurisprudência mecânica", alguns "jusnaturalismos" e etc.). O positivismo de Herbert L.A Hart tenta fugir desse dilema, mostrando de que maneira o Direito já operaria entre um e outro extremo, na existência de regras jurídicas identificáveis nos contextos sócio-práticos. Contudo, estaca diante dos tais casos difíceis, nas chamadas zonas de penumbra, em que relega a decisão à discricionariedade do juiz que atuaria como se fosse um legislador intersticial. É nesse ponto que Hart para no lugar em que seu aluno Ronald Dworkin começa chamando atenção para que mesmo nesses casos, para além das regras, ainda há algum padrão normativo atuando na decisão. Dworkin se vale, então da categoria normativa dos princípios para atacar o modelo de regras positivista. Estas primeiras críticas à discricionariedade judicial o levam a desenvolver uma teoria do Direito mais abrangente, que inclui em seu núcleo a famosa tese da resposta correta. (2017, p. 251). 
DOI 10.20873/uft.2359-0106.2021.v8n2.p202-220

Lenio Streck aponta para o fato de que há uma diferença entre decidir e escolher: a decisão ocorre no âmbito da razão prática e do agir estratégico, ao passo que o "decidir" implica em um ato estatal de responsabilidade política. (2017, p. 253).

Neste aspecto, conclui Streck que a "democracia sempre corre perigo se a aplicação do Direito pelos juízes e Tribunais é feita sem uma adequada teoria da decisão judicial, enfim, de uma criteriologia e, finalmente, sem mirar em uma resposta correta [...]" (2017, p. 253).

Com efeito, Streck, sem deixar de observar a diferença entre os sistemas common law e civil law, aproxima Gadamer e Dworkin ao desenvolver sua tese de respostas corretas em Direito. Assim, para "alcançar a resposta correta - denominada na CHD de resposta adequada à Constituição", o Autor valeu-se da "imbricação da hermenêutica filosófica gadameriana com a teoria da 'law as integrity' de Dworkin, ambas importantes para a formação da Crítica Hermenêutica do Direito" (2017, p. 253). A resposta correta, sob esta ótica, perpassa pela utilização de determinados critérios (e da observância de certos princípios), de sorte que o juiz somente poderia deixar de aplicar a lei caso se fizessem presentes uma das seguintes hipóteses:

[...] (i) quando a lei for inconstitucional, ocasião em que deve ser aplicada a jurisdição constitucional difusa ou concentrada; (ii) quando estiver em face dos critérios de antinomias; (iii) quando estiver em face de uma interpretação conforme a Constituição; (iv) quando estiver em face de uma nulidade parcial com redução de texto; (v) quando estiver em face de uma inconstitucionalidade com redução de texto; (vi) quando estiver em face de uma regra que se confronte com um princípio, ocasião em que a regra perde sua normatividade em face de um princípio constitucional, entendido este como um padrão [...] $\mathrm{Na}$ busca da resposta correta (adequada a Constituição), existem, ainda, os cinco princípios/padrões que são fundantes da decisão jurídica [...] São eles: (i) Princípio um: a preservação da autonomia do Direito; (ii) Princípio dois: o controle hermenêutico da interpretação constitucional - a superação da discricionariedade; (iii) Princípio três: o respeito à integridade e à coerência do Direito; (iv) Princípio quatro: o dever fundamental de justificar as decisões; (v) Princípio cinco: o direito fundamental a uma resposta constitucionalmente adequada [...] (2017, p. 258/259). 
DOI 10.20873/uft.2359-0106.2021.v8n2.p202-220

O Autor conclui que decidir é "agir com responsabilidade política", porquanto implica na "responsabilidade de aplicar o Direito corretamente. Uma questão de princípio: garantir os direitos de quem efetivamente os possui." (2017, p. 268). Pode-se concluir, portanto, que a figura do juiz Hércules mostra como um magistrado deve esforçar-se para interpretar os deveres e direitos advindos da comunidade de princípios; e Lenio Streck contribui com a adaptação da teoria de Dworkin para o ordenamento jurídico brasileiro.

\section{CONSIDERAÇÕES FINAIS}

As teorias ou paradigmas da tomada da decisão judicial constituem questão importante para qualquer estudo que se proponha a analisar temáticas vinculadas ao Poder Judiciário, tais como: a teoria da tripartição dos poderes de Montesquieu; o ativismo judicial; as funções contramajoritária e representativa do Judiciário; a produção de provas no processo; a efetividade dos direitos fundamentais, entre outros temas relevantes e atuais.

Diversos autores debruçaram-se acerca do tema. A título exemplificativo, cita-se Herbert Hart, Ronald Dworkin e Lenio Streck. No caso específico de Ronald Dworkin, a decisão judicial pressupõe a compreensão do Direito como integridade e, conforme desenvolvido anteriormente, implica no entendimento de que as pessoas estão em uma comunidade de princípios (diametralmente oposta a uma sociedade utópica, justa e perfeitamente imparcial), o que franqueia à política comum o conflito entre os ideais de justiça e equidade.

$\mathrm{Na}$ verdade, o Autor advoga pela existência de negociação e de acordos entre os ideais dos grupos da sociedade, para que não haja uma legislação que aplique a vontade de uma maioria. No que tange à aplicação de princípios, Dworkin sugere que cada grupo tenha voz, a fim de que a decisão coletiva fundamente-se em um princípio 
coerente; ou seja, é necessário atingir um meio-termo por intermédio de um espaço público de diálogo, ideia esta adotada por Hannah Arendt. Como a comunidade de princípios é um terreno que aceita a divergência de ideias, o diálogo contendo o conceito de poder da Autora mencionada é imperioso, na medida em que este é desvinculado da noção de violência e identificado com a ação de alcançar-se um acordo comum entre os indivíduos da sociedade. Conclui-se que fazer parte de uma comunidade de princípios traduz-se em ter acesso a espaço público de diálogo, o que implica na sensação de pertencimento e de efetividade dos direitos humanos.

A figura do juiz Hércules mostra como um magistrado deve atuar perante o cenário da comunidade personificada, eis que os direitos e deveres seriam advindos desta; ou seja, a admissão de que exista uma resposta correta ou, ainda, a percepção de que o magistrado deve esforçar-se interpretativamente para encontrar a resposta correta tem como consequência o reforço da comunidade de princípios e a pressuposição de que é uma prerrogativa do jurisdicionado receber uma decisão do Judiciário capaz de inferir qual é o Direito aplicável ao caso concreto.

É importante ressaltar que o magistrado é assimilado à figura de um romancista em cadeia, porquanto deve buscar criar um romance unificado, com base na interpretação dos casos precedentes. Ele, ainda, deve pensar além da matéria jurídica, tendo em vista o bem-estar comunitário e as implicações futuras da decisão. A contribuição de Lenio Streck, neste sentido, adapta-se à teoria de Dworkin, desenvolvida sob a égide do sistema common law ao sistema romano-germânico, próprio da experiência brasileira, ainda que existam algumas aproximações com o sistema common law.

Neste sentido, futuras pesquisas a respeito do tema poderão debruçar-se tanto no que concerne à adaptação da teoria da tomada da decisão judicial elaborada por Dworkin no sistema romano-germânico (o qual, ao menos no Brasil, sofre influências do sistema common law por meio da crescente importância dos precedentes), quanto à importância da comunidade de princípios para a efetivação dos direitos fundamentais, 
na linha do que foi desenvolvido por Hannah Arendt na obra intitulada Origens do totalitarismo.

\section{REFERÊNCIAS}

ARENDT, Hannah. A condição humana. Rio de Janeiro, Forense, 2010.

ARENDT, Hannah. Origens do totalitarismo. São Paulo: Companhia das Letras, 1989.

BITTAR, Eduardo. Introdução ao estudo do direito: humanismo, democracia e justiça; 2. ed. rev. e ampl. São Paulo: Saraiva, 2019.

DWORKIN, Ronald. O império do direito. São Paulo: Martins Fontes, 1999.

DWORKIN, Ronald. Uma questão de princípio. São Paulo: Martins Fontes, 2000. HART, Herbert. O Conceito de Direito. Lisboa: Fundação Calouste Gulbenkian, 2007. STRECK, Lenio. Dicionário de Hermenêutica: quarenta temas fundamentais da Teoria do Direito à luz da Crítica Hermenêutica do Direito. Belo Horizonte (MG): Letramento, 2017. 